\title{
Controlling of Saltwater Intrusion Using Injection Wells (Case Study: Quaternary Aquifer of Delta Wadi El-Arish, Sinai)
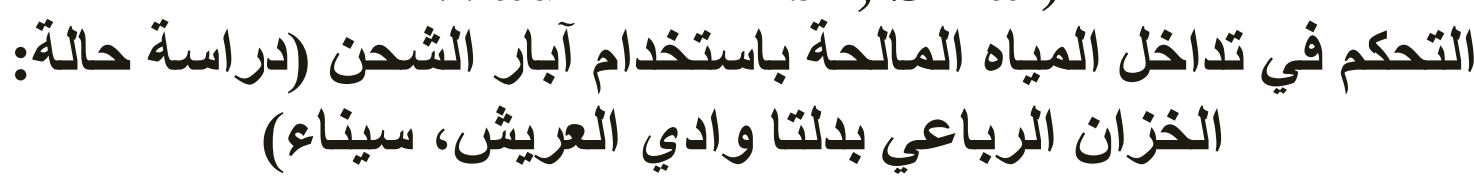

\author{
Kassem S. El-Alfy ${ }^{1}$, Hamdy A. El-Ghandour², Mahmoud E. Abd-Elmaboud ${ }^{3}$ \\ ${ }^{1}$ Professor of Hydraulics, Irrigation \& Hydraulics Dept., Fac. of Engrg., \\ Mansoura Univ., Mansoura, Egypt. \\ ${ }^{2}$ Assistant Professor, Irrigation \& Hydraulics Dept., Fac. of Engrg., Mansoura \\ Univ., Mansoura, Egypt \\ ${ }^{3}$ M.Sc. Student, Irrigation \& Hydraulics Dept., Fac. of Engrg., Mansoura Univ., \\ Mansoura, Egypt.
}

\begin{abstract}
الخلاصة

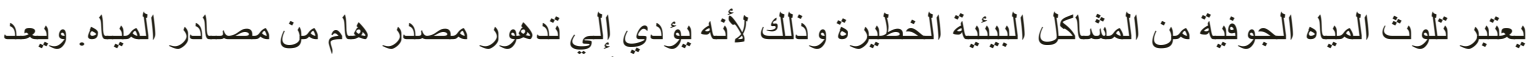

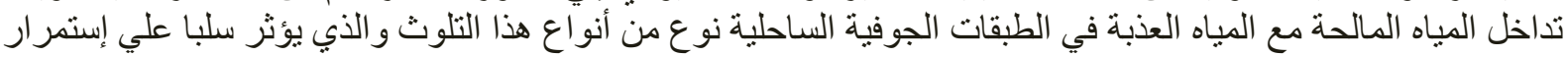

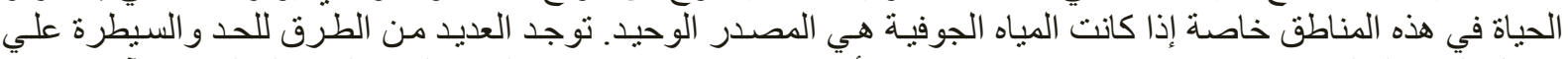

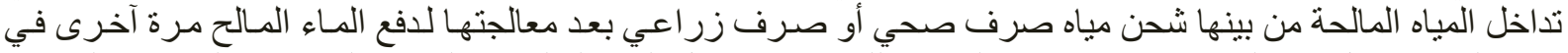

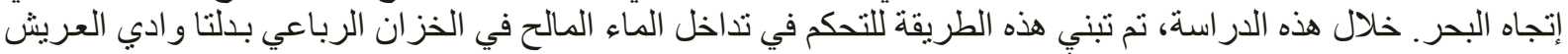

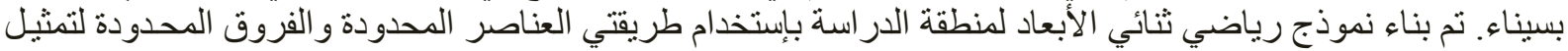

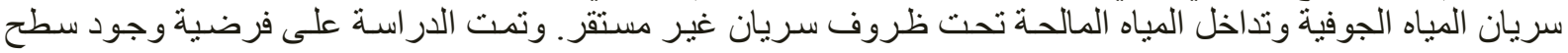

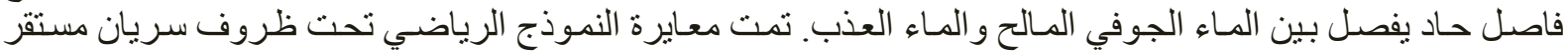

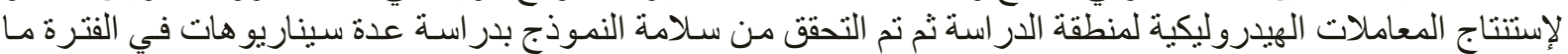

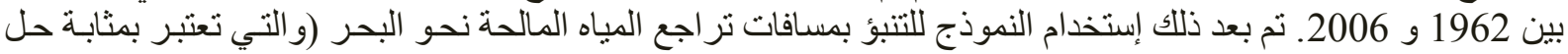

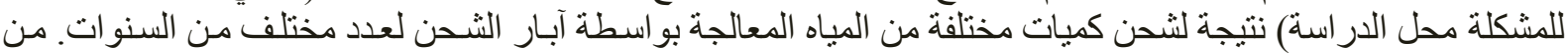

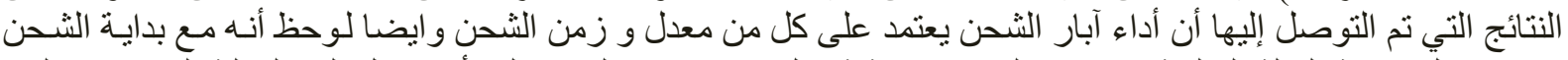

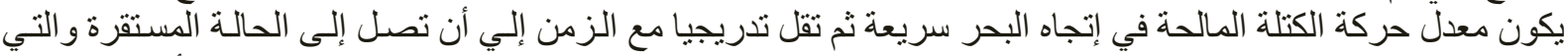

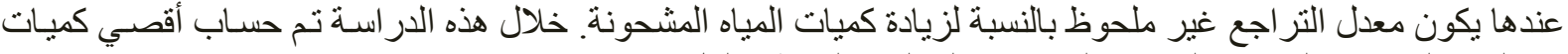
من المياه المشحونة لعدد مختلف من السنو مغرات و التكاليف المناظرة لكل منها.
\end{abstract}

\begin{abstract}
Groundwater contamination is a very serious problem as it leads to the deterioration of groundwater resources. Saltwater intrusion is a special category of groundwater contamination that threatens the health and possibly lives of many people living in coastal areas. The installation of injection of treatment water is among several methods proposed to control saltwater intrusion on coastal groundwater system. In this research, a twodimensional numerical model is developed for simulating both groundwater flow and saltwater intrusion of Quaternary Aquifer in Delta Wadi El-Arish (QADWA). The sharp interface philosophy is adopted to simulate dynamics of freshwater flow. The proposed model applied a coupled Finite Element Method (FEM) and Finite Difference Method (FDM) to predict the temporal migration of interface toe due to injection of treatment water. Model calibration is carried out to determine the physical parameters of the proposed model. Then, model verification and validation are established by comparing model results with the actual measurements. This study is considered a trial to present a solution for the problem of saltwater intrusion by finding general relationships between average distances of saltwater intrusion and injected rates of treatment water. Then, the suitable value of recharged water can be mathematically determined. The results obtained from this study are useful in management schemes of saltwater intrusion mitigation in coastal areas.
\end{abstract}




\section{Keywords}

Saltwater intrusion, Finite Element Method, Sharp interface, Injection wells, Quaternary aquifer.

\section{Introduction}

Groundwater is considered a reliable source of freshwater, in coastal regions, for a variety of purposes including domestic, industrial and irrigational uses. The irregular withdrawal of groundwater from these regions causes a serious environmental problem called saltwater intrusion problem. The main causes of this problem are overabstraction of the aquifer, which considered the main reason for the problem, short term implication (e.g. tidal effect and seismic waves), and long term implication (e.g. climate change and other periodic change such as seasonal change in natural groundwater) (Bear et al., 1999). Consequently, the planning and management of coastal aquifers require special treatment. A number of experimental, analytical and numerical models have been adopted to study saltwater intrusion problem. These studies attempted to locate the position of freshwater-saltwater interface and predict the changes in groundwater levels and salinity. Mathematical models of saltwater intrusion are commonly adopted one of the two approaches for representing the freshwatersaltwater interface. The first approach is based on the Ghyben-Herzberg relationship which assumes that the saltwater and freshwater are immiscible fluids and a sharp interface exists between the two fluids (Bear, 1979). In the second approach, saltwater and freshwater are treated as miscible fluids separated by a transition zone that is controlled by hydrodynamic dispersion (Bower et al., 1999). Bear (1979) suggested that the sharp interface approximation is appropriate if the transition zone thickness is thin relative to the depth of aquifer.

Extensive research is being carried out in many parts of the world with the objectives of understanding the mechanism of saltwater intrusion and improving the methods to control it, in order to protect groundwater resources in coastal aquifers. The key to control saltwater intrusion is to maintain a proper balance between water being pumped from the aquifer and water recharged into the aquifer. Todd (1974) presented various methods to prevent saltwater from contaminating groundwater sources such as: reduction of pumping rates, relocation of pumping wells, use of subsurface barriers, natural recharge, artificial recharge, abstraction of saline water and combination techniques. EL-Ganainy et al. (1995) investigated the effect of pumped wells on saltwater intrusion in coastal aquifer by using a quasi-three dimensional steady state areal finite element model. Sharp interface assumptions was adopted and confined and unconfined aquifers were considered. Mahesha (1996) studied the effect of battery of injection wells on saltwater intrusion in coastal confined aquifers. He studied various conditions by changing the well spacing, intensity and duration of injection freshwater. He concluded that, spacing between wells, injection rates and duration of injection control the repulsion of the saline wedge. Sabi et al. (1998) applied finite element method for studying the steady state saltwater intrusion assuming sharp interface philosophy. Sabi et al. (2001) developed finite element model to predict the interface position in steady and transient conditions. The model was applied on the coastal aquifer of Martil, Morocco, to study the aquifer responses for changing in recharge and total rate of pumping water and their effects on saltwater intrusion. Liles et al. (2001) applied MODFLOW software to control the saltwater intrusion problem by forecasting injection quantities and well locations. Bakker (2003) developed a threedimensional finite difference model for confined coastal aquifer taking into consideration the sharp interface between freshwater and saltwater and application of Dupuit approximation. A new mathematical 
formulation was presented for regional saltwater intrusion in aquifer systems. Also, he studied the upcoming below a pumping well. Mukhopadhyay et al. (2004) presented a laboratory study to investigate the effect of artificial recharge on the aquifer material properties such as: porosity and permeability. Van Meir et al. (2004) used in situ laboratory for characterizing the saltwater intrusion process in a hard rock aquifer with an appreciable level of heterogeneity. Rastogi et al. (2004) developed steady state numerical model to control the saltwater intrusion problem involving hydrodynamic dispersion in synthetic multi-layered confined coastal aquifers. Two scenarios were studied: the effect of freshwater recharge, and combination of freshwater recharge and saltwater discharge wells. Bajjali (2005) applied geostatistical techniques to examine the effect of recharge dams on groundwater quality. The infiltrated water below the dams increases the aquifer storage of freshwater and pushes the saline water toward the sea. El-Ghandour (2005) analyzed various patterns of external loads on saltwater intrusion, under steady state conditions, which affect the studied coastal aquifers. Also, a genetic algorithm model was presented to manage some coastal aquifers. Harne et al. (2006) presented a two dimensional sub-surface transport model of saltwater considering the homogenous and isotropic soil under the influence of constant seepage velocity. They used the finite difference method to solve the transport equation. The model examined the efficiency of subsurface barrier to control saltwater intrusion. Goswami and Clement (2007) used sand tank experiments to develop modeling-benchmarking results for the situations of steady-state, intruding and receding interface conditions, for the lateral saltwater intrusion case. Sherif and Kacimov (2008) applied SUTRA software to examine different pumping scenarios in vertical view of coastal aquifer. They concluded that saltwater intrusion problems could be controlled through proper pumping of saline groundwater from the coastal zone. Javadi et al. (2012) applied simulation-optimization model to control saltwater intrusion in coastal aquifers. Several scenarios were studied such as: abstraction of brackish water, recharging of freshwater, and combinations of the abstraction and recharging.

Previous studies on the case study of Quaternary Aquifer in Delta Wadi El-Arish (QADWA), Sinai concerns only with the application of mathematical modeling to either determine the location of saltwater wedge or expecting the groundwater levels due to heavy pumping rate. While, the novelty of this research stems, for the first time, from introducing a probable solution for the problem of saltwater intrusion in the QADWA using injected freshwater by developing a two-dimensional numerical model for the aquifer using FEM. Also, the maximum expected values of injected water are computed and the corresponding costs are determined.

\subsection{Site Description}

Egypt is located in north-eastern Africa and includes the Sinai Peninsula, which is often considered as a part of Asia continent. Egypt's natural boundaries consist of more than 2900 kilometers of coastline along the Mediterranean Sea, the Gulf of Suez, the Gulf of Aqaba, and the Red Sea. Sinai Peninsula is approximately $380 \mathrm{~km}$ long and $210 \mathrm{~km}$ wide as shown in Figure (1), the surface area has extension of $61,000 \mathrm{~km}^{2}$. The groundwater is the main issue for developing in the Sinai Peninsula. North Sinai especially Delta Wadi El-Arish depends on groundwater as a main source for drinking, agricultural, industrial, and other purposes. The groundwater table in Delta Wadi El-Arish coastal aquifer is now below the mean sea level over a large area which indicates that the freshwater abstraction exceeding more than natural recharging. This aquifer is being supported by lateral inflow from adjacent aquifer, from depleting storage and from the return flow of domestic waste water (Abdelaziz and Bakr, 2012). 
Delta Wadi El-Arish is characterized by fanshaped outline with district borders. It is located between latitudes $31^{\circ} 00^{\prime} 00^{\prime}$ ', $31^{0}$ $11^{\prime} 00^{\prime}$ ' E, and longitudes $33^{\circ} 45^{\prime} 00^{\prime}, 33^{\circ}$ $56 ' 30 " \mathrm{~N}$ with an area of about $90 \mathrm{Km}^{2}$ as shown in Figure (1). It is located in the semiarid belt of Egypt which is characterized by hot summer, cold, rainy winter, and high evaporation rate. The main annual rainfall ranges from $60 \mathrm{~mm}$ to $80 \mathrm{~mm}$. The daily mean value of evaporation reaches 4 $\mathrm{mm}$ /day. The Delta of Wadi El-Arish has a special hydrographic significance sustained heavy pumping for irrigation. It is intensively cultivated by olive, data palms and vegetables (Gad et al., 2009).

Geologically, north Sinai is occupied by sedimentary rocks ranging in age from Triassic to Quaternary (Saad, 1981; Taha, 1968; and Gad et al., 2009). The Quaternary deposits form the main water-bearing formations in Delta Wadi El-Arish. They consist of sand dunes, old beach sand and the Kurkar. The thickness of these formations is about 80 to $100 \mathrm{~m}$ (JICA, 1992). Kurkar Formation consists of calcareous sandstone of shallow marine environment while the old beach sand consists mainly of fine to coarse sand intercalated with gravel and clayey layers. These deposits are conformably overlying the Kurkar in someplace with a thickness ranging from $20 \mathrm{~m}$ to $60 \mathrm{~m}$. On the other side, the sand dune deposits are extensively distributed along the coastal plain covering the old beach sand and locally intercalated with clay and gravel layers. The thickness of the sand dunes ranges between $20 \mathrm{~m}$ and $40 \mathrm{~m}$.

Based on the periodical inventory carried out by both staff of Water Resources Research Institute (WRRI) and Hassan (2010) show that the biggest depletion in the water level was recorded during the period 1980 and
1988 due to extensive pumping rates that consider more than the nature recharging volume. So the zero potentiometric contour line is expanded to enclose most El-Arish area between the airport in the south to ElArish in the north and in the west to ElArish-Rafah road in the east.

Figure (2) demonstrates the Lithology cross section along the study area of QADWA. Monitoring well line in N-S direction showing different water bearing zones (i.e. sand, gravel and Kurkar zones).

\section{Materials and methods}

\subsection{Governing Equations}

The three-dimensional groundwater flow equation in an unconfined aquifer is as follows (Bear, 1979):

$$
\begin{array}{r}
\frac{\partial}{\partial x}\left(K \frac{\partial h}{\partial x}\right)+\frac{\partial}{\partial y}\left(K \frac{\partial h}{\partial y}\right)+\frac{\partial}{\partial z}\left(K \frac{\partial h}{\partial z}\right)- \\
-N=S \frac{\partial h}{\partial t}
\end{array}
$$

in which, $K$ represents hydraulic conductivity; $S$ is the storage coefficient (dimensionless); $h$ is the hydraulic head of groundwater equal to $(z+p / \gamma) ; z$ is the elevation from a specified datum; $p$ is the pressure; $\gamma$ is the specific weight of the fluid; and $N$ is the recharge or withdrawal per unit surface area.

A Ghyben and Herzberg approximation assumed that no flow occurs in the saltwater region (Bear, 1979). Thus the focus is entirely upon the freshwater region. This region is divided into two zones. Zone (1) consists of the freshwater aquifer between the impermeable layer and groundwater table with no intervening saltwater while Zone (2) consists of the freshwater between groundwater table and the underlying saltwater as shown in Figure (3). 


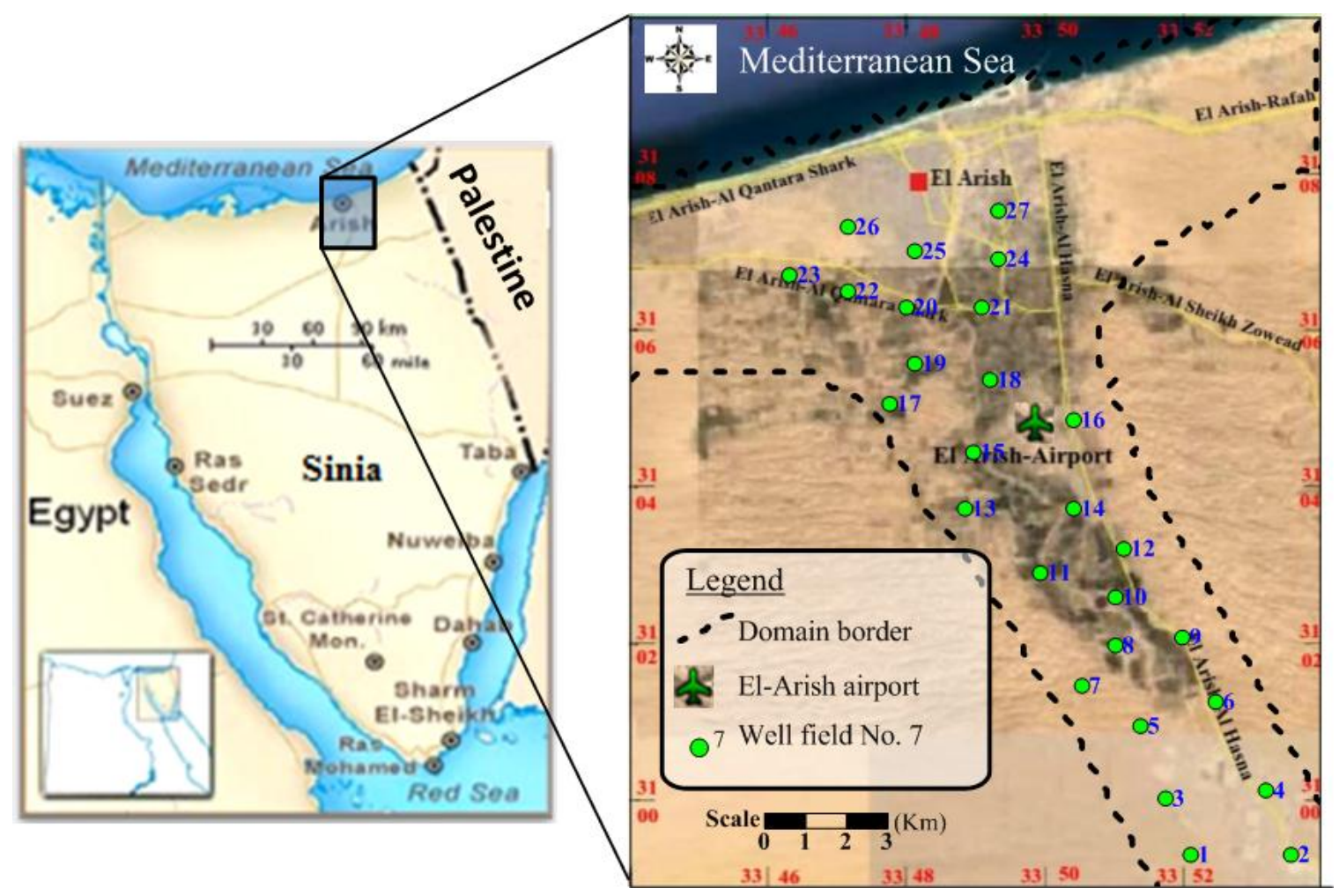

Figure 1: Location map of the Delta Wadi El-Arish showing the location of the tested well fields

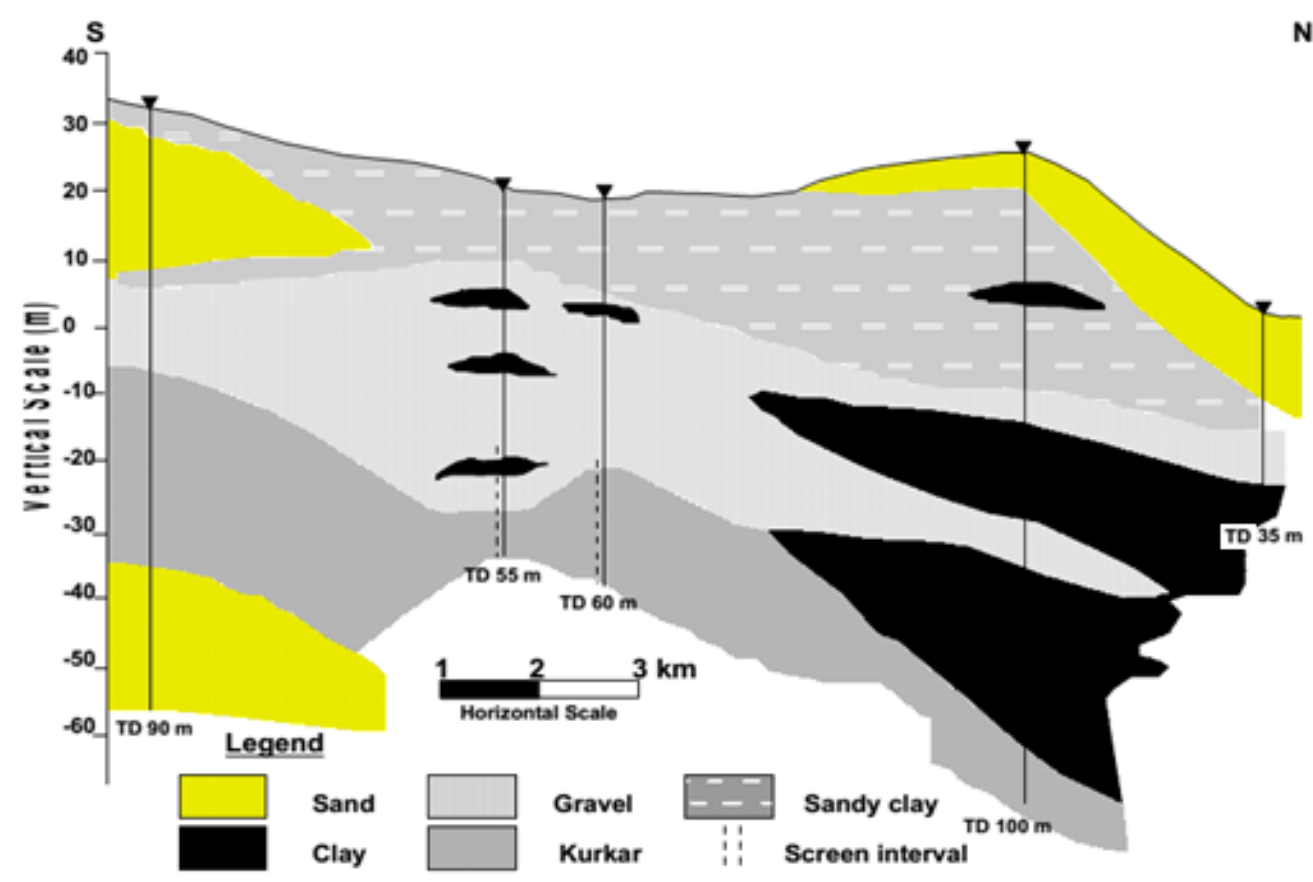

Figure 2: The lithology cross section along the QADWA 
The vertical integration of Eq. (1) in both Zones (1) and (2) after adopting the Dupuit assumption gives (Taigbenu et al., 1984):

for Zone (1):

$$
\frac{1}{2} K \nabla^{2} h_{1}^{2}-N=S \frac{\partial h_{1}}{\partial t}
$$

for Zone (2):

$$
\frac{K \gamma_{s}}{\Delta \gamma} \nabla^{2}\left(\frac{h_{2}^{2}}{2}-d h_{2}\right)-N=\frac{S \gamma_{s}}{\Delta \gamma} \frac{\partial h_{2}}{\partial t}
$$

in which, $\nabla^{2}=\frac{\partial^{2}}{\partial x^{2}}+\frac{\partial^{2}}{\partial y^{2}} ; h_{1}$ and $h_{2}$ are the hydraulic heads corresponding to freshwater in Zone (1) and Zone (2) respectively as shown in Figure (3); $\Delta \gamma=\left(\gamma_{s}-\gamma_{f}\right) ; \gamma_{f}$ and $\gamma_{s}$ are the specific weights of the freshwater and saltwater respectively; and $d$ is the elevation of the mean sea level (M.S.L) from a specified datum as shown in Figure (3).

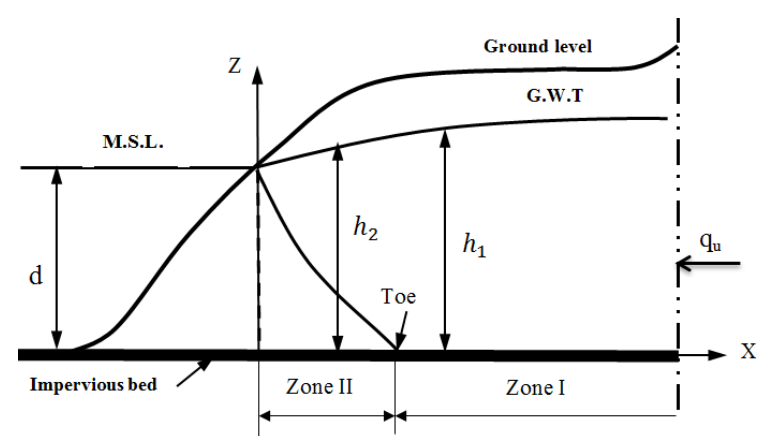

Figure 3: Definition sketch for coastal unconfined aquifer

Wang and Tsay (2001) depend on Strack (1989) to develop the following two equations corresponding to Zone (1) and Zone (2) by replacing both the dependent variable $h_{1}$ and $h_{2}$ with the potential $\varnothing$ as follows:

for Zone (1):

$$
\begin{array}{r}
\frac{\partial}{\partial x}\left(K \frac{\partial \emptyset}{\partial x}\right)+\frac{\partial}{\partial y}\left(K \frac{\partial \emptyset}{\partial y}\right)-N= \\
=S(2)^{1 / 2} \frac{\partial \emptyset^{1 / 2}}{\partial t}
\end{array}
$$

for Zone (2):

$$
\begin{array}{r}
\frac{\partial}{\partial x}\left(K \frac{\partial \emptyset}{\partial x}\right)+\frac{\partial}{\partial y}\left(K \frac{\partial \emptyset}{\partial y}\right)-N= \\
=S\left(\frac{2 \gamma_{s}}{\Delta \gamma}\right)^{1 / 2} \frac{\partial \emptyset^{1 / 2}}{\partial t}
\end{array}
$$

Values of both $h_{1}$ and $h_{2}$ can then be calculated from the following equations: for Zone (1):

$$
h_{1}=\sqrt{2 \varnothing+\frac{\gamma_{s}}{\gamma_{f}} d^{2}}
$$

for Zone (2):

$$
h_{2}=\sqrt{\frac{2 \emptyset \Delta \gamma}{\gamma_{s}}}+d
$$

In the subsequent use of Eqs. (4) and (5), it is necessary that RHS to be linear. The linearization is used whereby $\partial \emptyset^{1 / 2} / \partial t$ is written as $1 /\left(2 \emptyset^{1 / 2}\right) \partial \varnothing / \partial t$ (Brutsaert and Ibrahim, 1966; Hantush, 1968; Taigbenu et al., 1984). Then a regional average $(\bar{\varnothing})$ is taken for the $\varnothing$ outside of the derivative. Thus Eqs. (4) and (5) is approximated by:

$\frac{\partial}{\partial x}\left(K \frac{\partial \emptyset}{\partial x}\right)+\frac{\partial}{\partial y}\left(K \frac{\partial \emptyset}{\partial y}\right)-N=S \lambda \frac{\partial \emptyset}{\partial t}$

where, $\lambda$ is constant equal to $\sqrt{1 / 2 \bar{\varnothing}}$ at zone (1) and $\sqrt{1 / 2 \Delta \gamma \bar{\varnothing}}$ at zone (2) for confined aquifer and equal to $\sqrt{1 / 2 \bar{\varnothing}}$ at zone (1) and $\sqrt{\gamma_{s} / 2 \Delta \gamma \bar{\varnothing}}$ at zone (2) for unconfined aquifer.

The average $\bar{\varnothing}$ must either be constant or a function of the spatial variable (Taigbenu et al., 1984). For the unsteady numerical study of this paper, $\bar{\varnothing}$ is taken as given by Taigbenu et al. (1984), since they relaxed the time independence of $\bar{\varnothing}$ and then adjusted such that mass was conserved at all times.

\subsection{Model Numerical Formulations}

The Finite Element Method (FEM) is coupled with a fully backward Finite Difference Method (FDM), in time, to solve the governing Eq. (8). FEM can handle any domain with complex boundaries. Also, heterogeneity and anisotropic characteristics can easily be included. The idea of the FEM is to discretize the domain under consideration to number of elements. Rectangular elements, bounded with four nodes, are chosen in the present work. A trial function is assumed to simulate the dependent variable within different elements. This trial function is usually assumed as a 
polynomial with a degree specified from number of nodes per element. A weak form for the governing equation is constructed. Galerkin form is selected, by minimizing the residuals of the selected weak solution at different nodes; the unknown dependent variables can be estimated (Burnett, 1987).

Based on both the FEM and FDM procedures, the matrix form of Eq. (8) is as follows:

$$
\begin{aligned}
{\left[\frac{1}{\Delta t_{n}}[C]+[A]\right]\{\Phi\}_{n}=} & \\
& =[F]_{n}+\frac{1}{\Delta t_{n}}[C]\{\Phi\}_{n-1}
\end{aligned}
$$

in which, $C$ is the capacity matrix; $A$ is a square matrix for the coefficients known as stiffness matrix; $\Phi$ is the unknown vector of potential; $F$ is a vector which contains the boundary fluxes; $\Delta \mathrm{t}$ is the time step equal to $\left(t_{n}-t_{n-1}\right), \quad n=0,1,2, \ldots . i$ and $i$ is the number of time intervals.

An original code is written using the FORTRAN language to program the proposed model. This code implements the principles of the coupled FEM and FDM procedures. The flow chart of the proposed model is presented in Figure (4).

\subsection{Conceptual Model}

To simulate the groundwater flow in Delta Wadi El-Arish aquifer, a conceptual model is adopted. The conceptual model is interested by hydrogeological understanding of how water flows into, through and out of a groundwater system. The most representative conceptual models depend on the material used in the corresponding study such as, collecting groundwater intake database and water sampling for physical and chemical analyses. In this study, most of the groundwater database includes collection of archival data and measurement of discharge; distribution of wells; piezometric heads; and recording potential sources for quality changes given by the central laboratory of the Desert Research Center. The constructed conceptual model depends on the following facts ( $\mathrm{Gad}$ et al., 2009;
Hassan, 2010; and Abdelaziz and Bakr, 2012):

- The QADWA consists of three different formations that is composed mainly of sand; Gravel and Sand; and Calcareous sandstone (Kurkar). In this paper vertical homogeneity was assumed, so the three layers have been merged to constitute a single equivalent layer with an equivalent permeability. Aquifer thickness equal to the sum of three layers average thicknesses.

- The groundwater in QADWA occurs under unconfined conditions.

- A number of 27 field wells representing the main discharging sources in QADWA as shown in Figure (1).

- There are several sources of recharge including infiltration from rainfall, return water from the imported Nile river water to the area, and recharge due to domestic water use.

\subsection{Model Grid}

The main step to start the simulation procedure is to divide the domain of QADWA into a suitable grid pattern. The study domain is $16 \mathrm{Km}$ in length (El-Arish sea-coast) and $18 \mathrm{Km}$ inland length. The model was constructed with a grid of rectangular element. Dimension of each element is $200 \times 200 \mathrm{~m}^{2}$. It covers an area of $180 \mathrm{~km}^{2}$. The computational grid was divided into 100 rows and 80 columns as illustrated in Figure (5). 


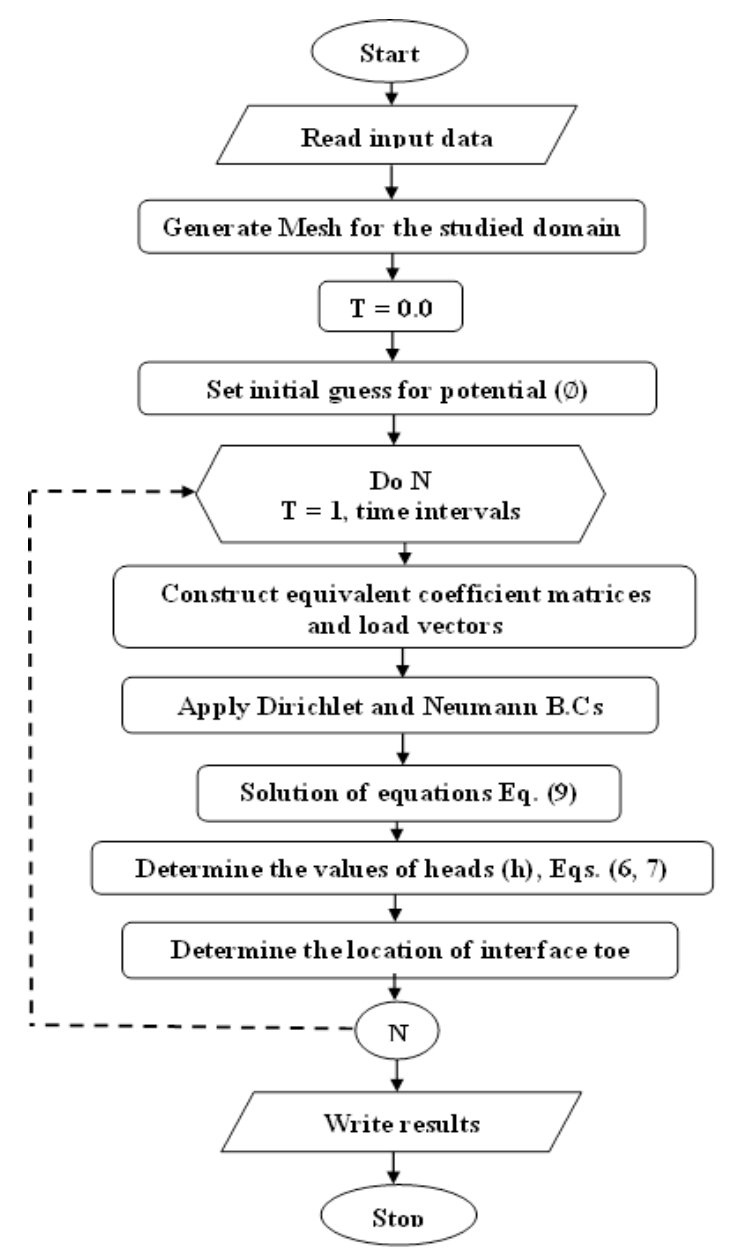

Figure 4: Flow chart for the proposed model

\subsection{Boundary Conditions}

The boundary conditions used in this model are defined in Figure (5). The Mediterranean Sea borders the model area in the north. So, this boundary was defined as a constant head boundary $(\phi=0)$. In the south, represent the inlet of flow for QADWA. So boundary has been considered as timely variable constant head boundary $\left(\partial \phi / \partial n=q_{u} / k\right)$ in which $q_{u}$ represents uniform rate of recharge per unit width of the aquifer. The eastern and western boundaries were considered as no-flow boundaries $(\partial \phi / \partial n=0)$. The seepage faces of the fresh water above Mean Sea Level (M.S.L) and around different wells are ignored within the present study.

\subsection{Model Calibration}

In this section, the model calibration was carried out using available point measurements of the flow parameters and hydrological measurements collected from previous studies. In the present study, both the hydraulic conductivity and the recharge are assumed spatially variable unknowns. The steps of calibration are as follows:

- Step (1): Zones of recharges are selected based on the analysis of Google earth map, Figure (1).

- Step (2): Values of hydraulic conductivity are estimated in case of steady state analysis of the model using the available data in the year of 1988. This achieved by putting the time dependent term (i.e. RHS) in Eq. (8) equal to zero.

- Step (3): The calibration of transient flow is carried out in the period between 1962 and 1988 by adjusting both the storativity and the net recharge values.

- Step (4): the calibrated model is validated by simulating the aquifer system for 18 more years starting from 1988 to 2006 .

In the first step of calibration, the Google earth map shows vegetated areas where expected returned irrigated water can recharge the aquifer. Calibrated recharge values should reflect recharge due to rainfall, returned water from different water uses and possible unknown recharge from other underlying formations not accounted here, Figure (6). This figure shows that the estimated net recharge varies between $1.2 \times 10^{-5}$ $\mathrm{m}$ /day (which exists in areas of recharge due to infiltration solely from rainfall) and $4.0 \times 10^{-3} \mathrm{~m} /$ day (which are combination effects of rainfall, irrigation and other possible sources) (Abdelaziz and Bakr, 2012). 


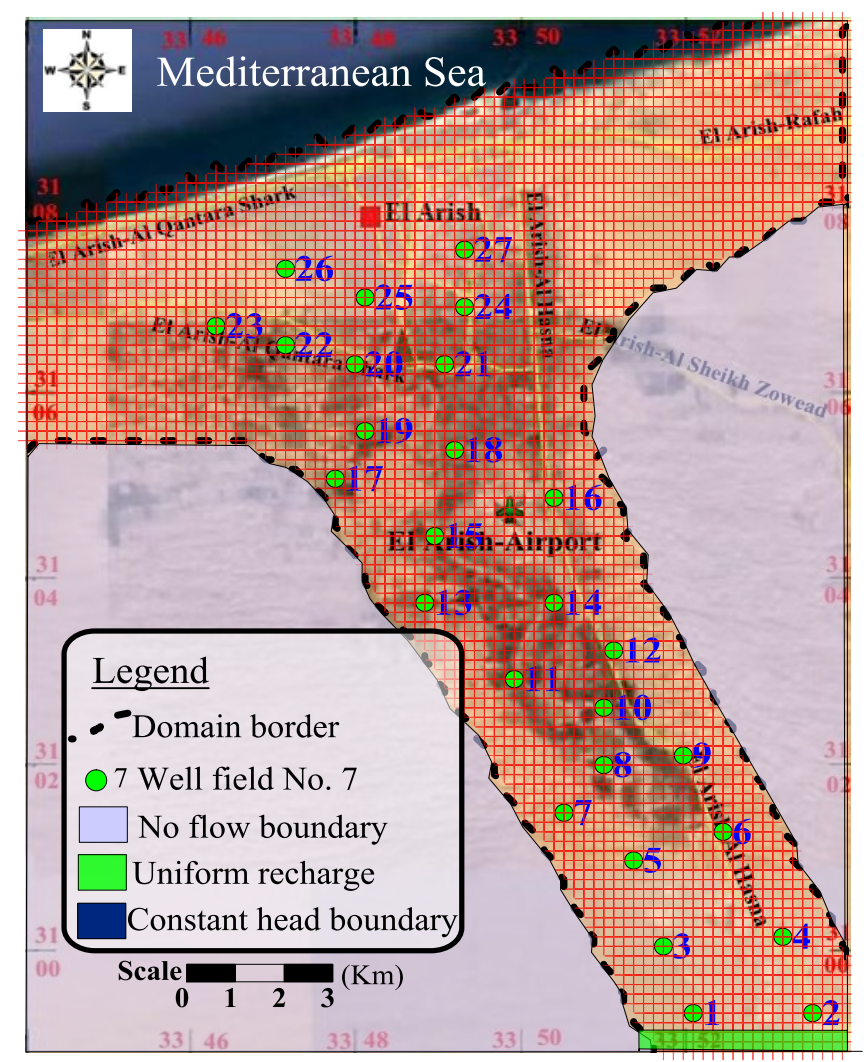

Figure 5: The grid of the studied domain of QADWA and boundary conditions used in this study

In the second step of calibration, the model is calibrated under steady state conditions using the collected measurement in the year of 1988. The following parameters are considered in the calibration: the annual pumping rate equal to 14.0 Million Cubic Meters (MCM) (Gad et al., 2009), depth of the (M.S.L) from the impervious bed $(d)$ equal to $40 \mathrm{~m}$, the specific weights of the freshwater $\left(\gamma_{f}\right)$ equal to $1000 \mathrm{Kg} / \mathrm{m}^{3}$ and the specific weights of the saltwater $\left(\gamma_{s}\right)$ equal to $1025 \mathrm{Kg} / \mathrm{m}^{3}$. Values of hydraulic conductivity are predicted using the model given by Abdel-Gawad (1999). Within the FEM procedure any studied aquifer can be considered heterogeneous by adopting different magnitudes of hydraulic conductivity for every element. Hydraulic conductivity within any element of the studied aquifer is created from a normal random distribution. The logarithms of hydraulic conductivity can be represented by the first two moments (the mean $\mu$ and the standard division $\delta$ ) as follows (AbdelGawad, 1999):

$$
\ln K_{i}=\mu+u_{1} \delta, \ln K_{i+1}=\mu+u_{2} \delta \text { (10) }
$$

where,

$$
\begin{aligned}
& i=1,3,5,7, \ldots \ldots n_{e} \\
& u_{1}=\left(-2 \ln \varepsilon_{1}\right)^{1 / 2} \cos \left(2 \pi \varepsilon_{2}\right), \\
& u_{2}=\left(-2 \ln \varepsilon_{1}\right)^{1 / 2} \sin \left(2 \pi \varepsilon_{2}\right)
\end{aligned}
$$

in which, $K_{i}$ and $K_{i+1}$ are the values of hydraulic conductivity for the two elements $i$ and $(i+1)$ in the studied discretized domain; $u_{1}$ and $u_{2}$ are normally distributed random numbers with mean equal to zero and standard division equal to $1 ; \varepsilon_{1}$ and $\varepsilon_{2}$ are independent uniform random numbers distributed in range from 0 to 1 ; and $n_{e}$ is the number of elements in the studied domain.

The studied domain is divided into five parts (i.e. east north, west north, middle north, airport, and south) (Abdelaziz and Bakr, 2012). Many trials have been performed to come up with the suitable values for both the 
mean $\mu$ and standard division $\delta$, depending on the actual values of hydraulic conductivities given by Abdelaziz and Bakr (2012). Finally, the following values are considered: in the east north part the values of $\mu=2.5$ and $\delta=0.5$; in the west north part the values of $\mu=1.2$ and $\delta=1.0$; in the middle north part the values of $\mu=3.5$ and $\delta=0.5$; in the airport part the values of $\mu=$ 4.5 and $\delta=0.4$; and in the south part the values of $\mu=4.7$ and $\delta=0.2$. A small code is originally developed, depending on the model shown in Eq. (10), to repeatedly generate two different values of hydraulic conductivity corresponding to each two elements in the studied domain. The generation of hydraulic conductivity values is continuously carried out until a good match between the observed and calculated heads are achieved, Figure (7-a).

Figure (7-b) shows both the calculated head and corresponding intrusion area in the year of 1988. The calibrated hydraulic conductivity in the studied domain is shown in Figure (8). This Figure shows that the calibrated hydraulic conductivity values range between values 0.5 and $100 \mathrm{~m} / \mathrm{d}$. It is seen from this figure that, the pattern of hydraulic conductivity being increasing monotonously with distance from the coast. The explanation of this noticeable depends on the Darcy's Law $\left(q_{n e t}=K A \frac{\partial h}{\partial x}\right)$ in which, $q_{n e t}$ is the net uniform discharge flow to the sea, $K$ is the hydraulic conductivity, $A$ is vertical cross sectional area for the studied domain (equal to the width of the studied domain multiplied by the assumed constant aquifer thickness, $40 \mathrm{~m}$ ), and $\frac{\partial h}{\partial x}$ is the rate of head changing with respect to distance from inland to coast. It is seen from this equation, both values of $q_{n e t}$ and $\frac{\partial h}{\partial x}$ are constants while value of $A$ decreases with distance from the coast, Figure (5). Consequently, $K$ values should increase with distance from the coast as the ( $\left.K A \frac{\partial h}{\partial x}\right)$ give the same value of $q_{n e t}$ through the aquifer.

The estimated pattern of hydraulic conductivity in each part is considered a probable realization in this part depending on the actual data.

In the third step of calibration, the calibration of transient flow is carried out in the period between 1962 and 1988 by adjusting both the storativity and the net recharge values. It is found that the suitable porosity equal to 0.02 along QADWA. Figure (9) shows both the calculated head and corresponding intrusion area in the year of 1962. To insure the validity of the calibrated model, the position of the interface toe in QADWA at 1962 is determined and drawn as the red dash line shown in Figure (9), using the historical data cited in Saad (1981). It can be seen from this figure, the determined interface toe nearly coincide the corresponding deduced one from calibration.

In the fourth step of calibration, the calibrated model is also validated by simulating the aquifer system for 18 more years starting from 1988 until 2006. During this period the annual pumping rates in QADWA increasing from 14.0 MCM in 1988 to $19.0 \mathrm{MCM}$ (Gad et al. 2009). So, the net recharge rate is adjusted according to increasing in the pumping rate. Figure (10) shows the estimated heads in the model domain of QADWA for 2006. Also, the relative absolute average error between calculated and observed heads is computed and it is found equal to 0.166 . It is found that the model results were very sensitive to the boundary conditions along the QADWA. In all selected years, the calculated heads are used to predict the saltwater intrusion zones (shaded areas) as illustrated in Figures (7-b), (9), and (10). 


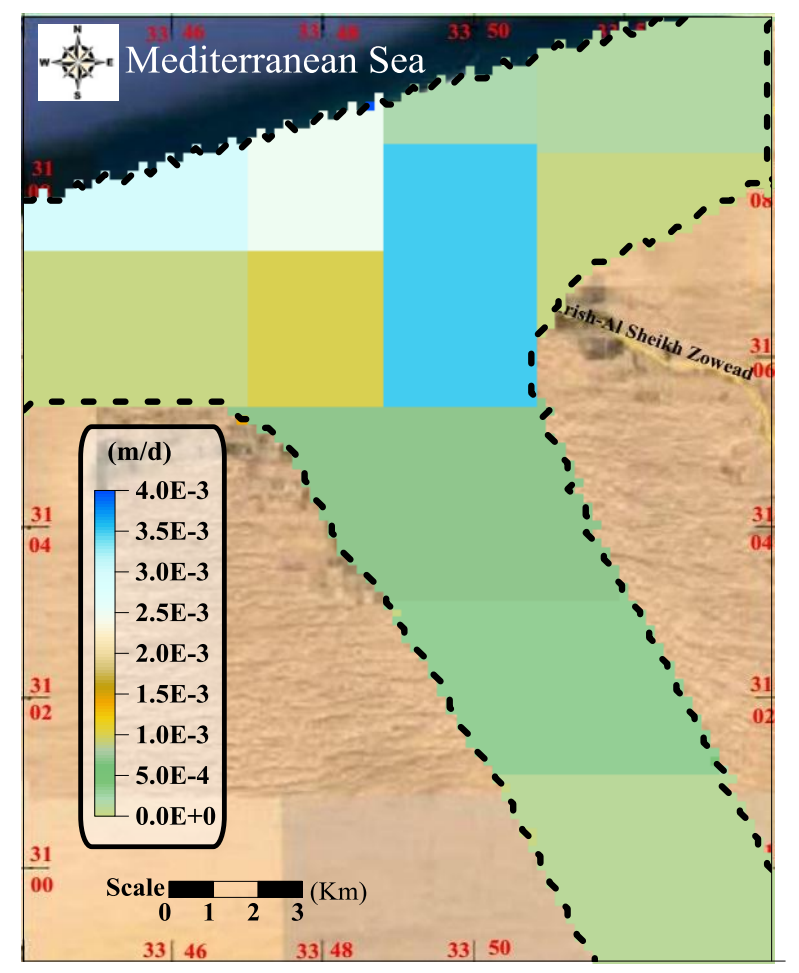

Figure 6: Values of calibrated recharge Zones
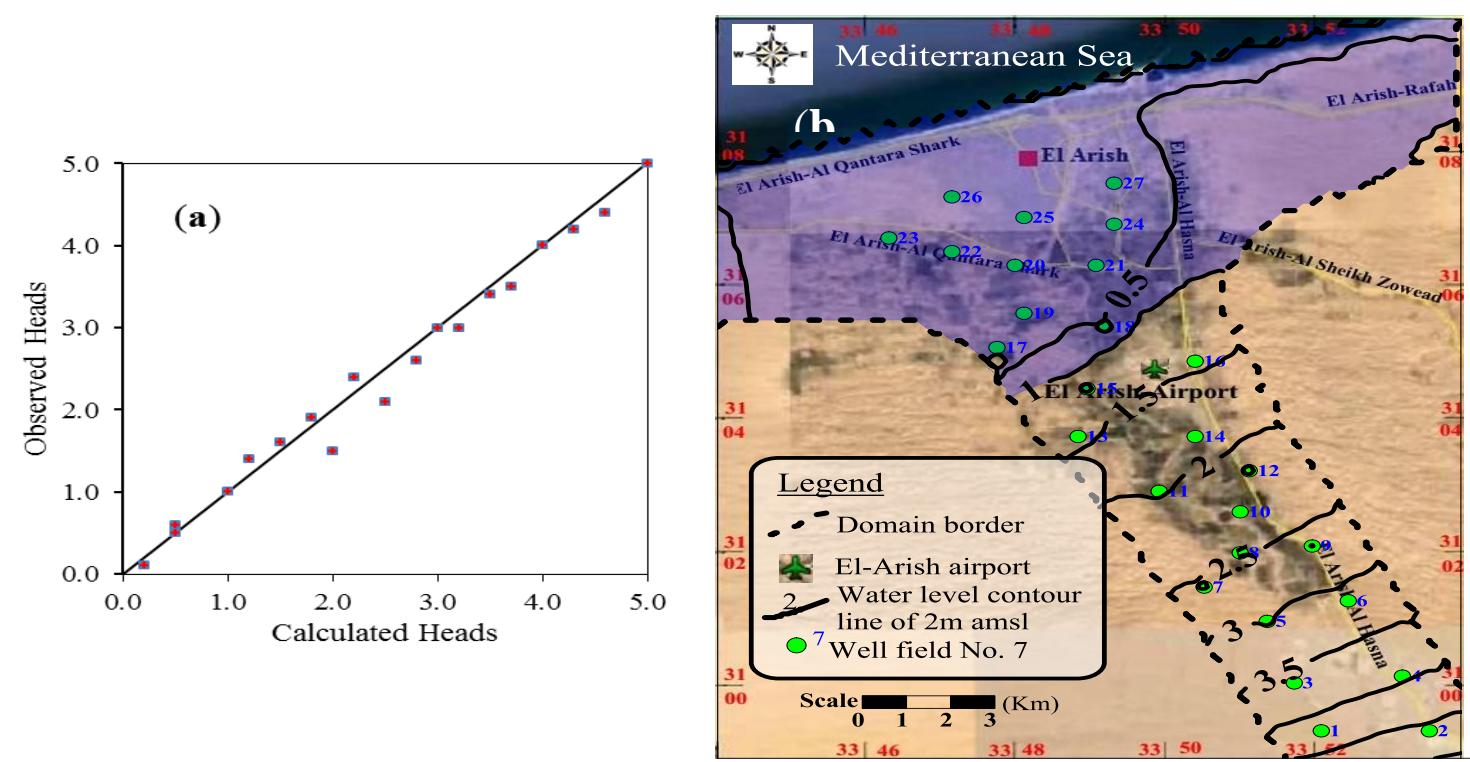

Figure 7: Comparison between observed and calculated hydraulic heads in the year of 1988 (left map) and the extension of saltwater intrusion area at 1988 (the shaded area in the right map) 


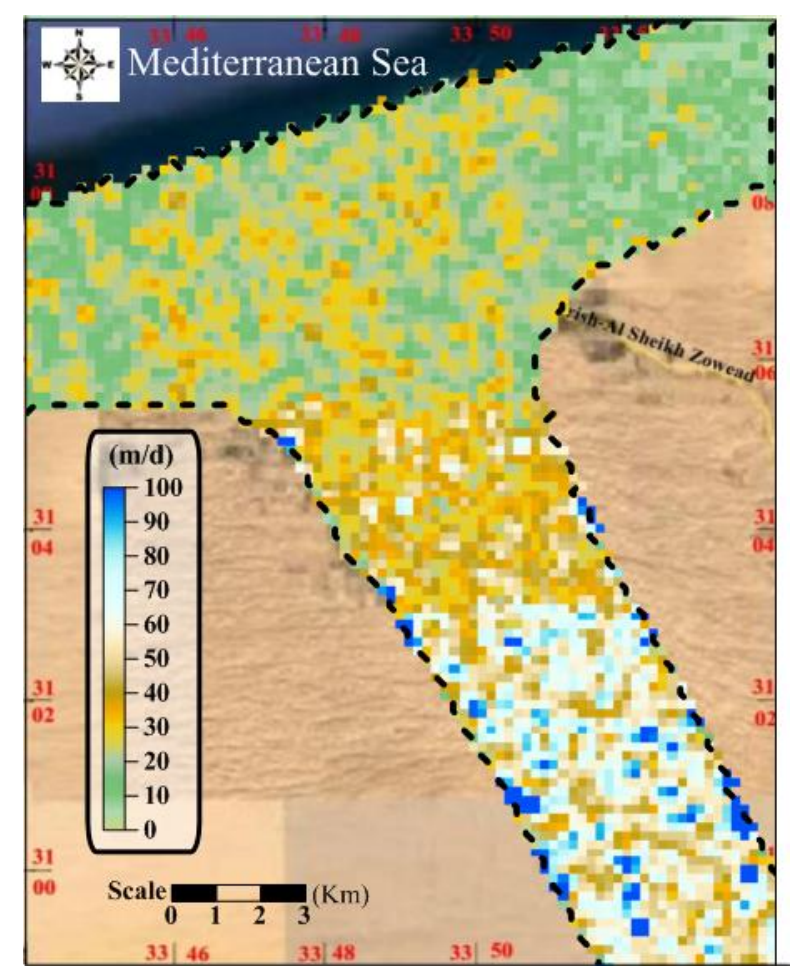

Figure 8: Values of calibrated hydraulic conductivity

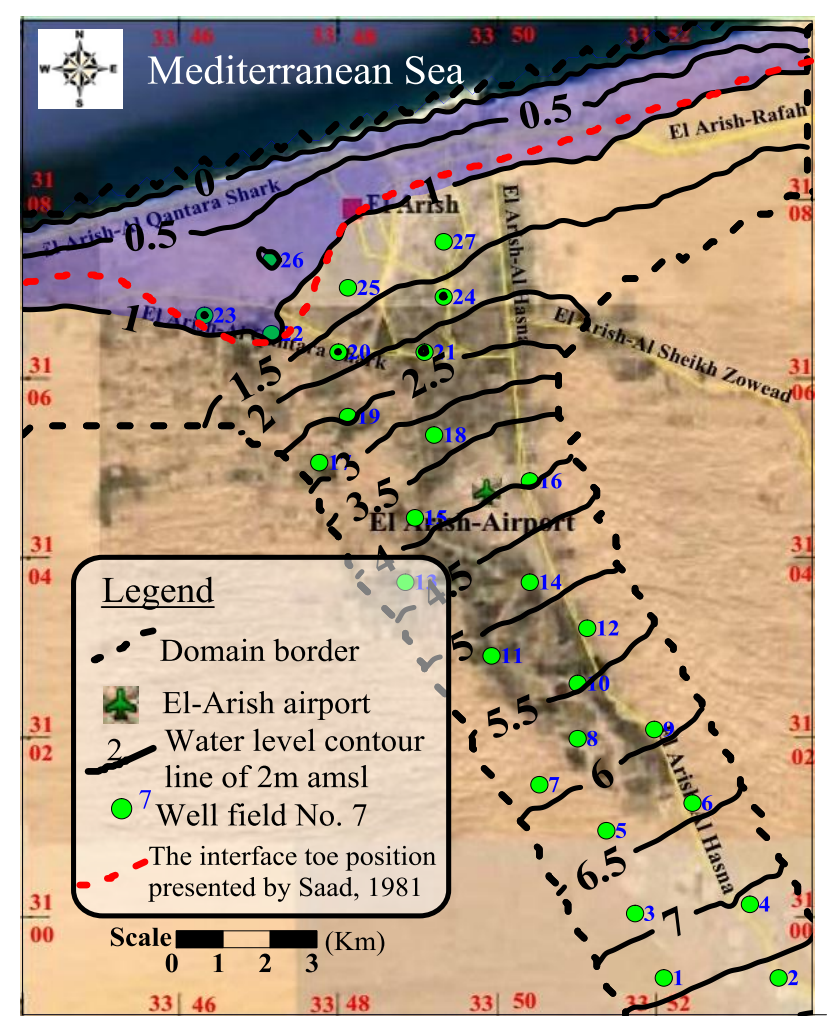

Figure 9: Contour lines of the calculated heads for 1962 and the shaded area refer to the saltwater intrusion area 


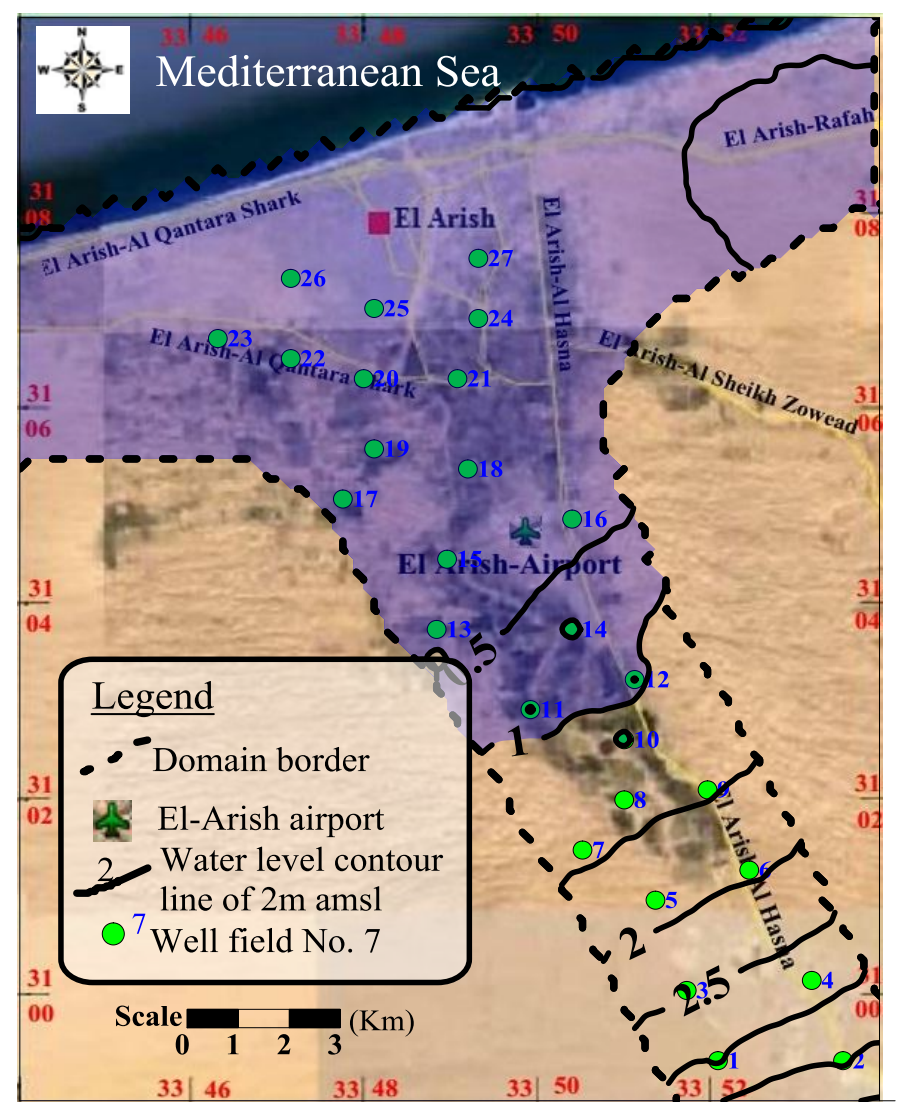

Figure 10: Contour lines of the calculated heads for 2006 and the shaded area refer to the saltwater intrusion area

\section{Results and discussion}

During last decades, to study the problem of saltwater intrusion in QADWA, the results of pumping tests show a sharp increasing of groundwater decline. This may be due to random drilling wells and over pumping to cover the requirements of water demands particularly in the coastal and central parts. In 1962, the migration of saltwater intrusion in QADWA was found at a distance of $1.0 \mathrm{Km}$ inland which extended along the eastern side of El-Arish - Rafah road and about $3.0 \mathrm{Km}$ at south west of ElArish city, Figure (9). After 26 years (in 1988), due to the increasing of population and cultivated areas, the interface toe is found to be at distance $3.0 \mathrm{Km}$ in land along the eastern side of El-Arish-Rafah road and about $6.5 \mathrm{Km}$ in land near to north El-Arish airport area, Figure (7-b). From 1988 to 2006, the long-term impact of the present pumping conditions (19 MCM) is expected in the present study. The results showed a continuous decline in groundwater levels, since the groundwater level ranges from 4.0 $\mathrm{m}$ above (M.S.L) in south to about zero above (M.S.L) in extreme north with general flow direction from south to north as shown in Figure (10). Due to the continuous decline in groundwater levels, the interface toe invaded the QADWA for a distance equals to $11 \mathrm{Km}$, Figure (10).

As expected, any increasing in annual pumping rate accelerates saltwater intrusion and accordingly increasing the intruded zone. The key to mitigate saltwater intrusion is to maintain a proper balance between water being pumped from the aquifer and water recharged to the aquifer. To mitigate saltwater intrusion in QADWA, the injection of freshwater method through battery of injection wells is chosen. Mahesha (1996) showed that the best location of injection wells at the position of interface toe. So the battery of the injection wells may be located at distance equal to $12 \mathrm{~km}$ from shore line 
(the expected interface toe location at 2013). Also, he showed that the better results are observed when the relation between spacing between the injection wells and initial position of interface toe from the coast line is less than or equal $10 \%$. If this ratio is greater than $10 \%$, the undulating trend in repulsion of the saline wedge is observed, and consequently isolated saline wedges are formed between the wells. So, in this study the spacing between field wells is taken equal to $800 \mathrm{~m}$. The present work studies various conditions such as changing in both the intensity and duration of freshwater injection. The source of injected water can be found from the treatment wastewater, since about $50,000 \mathrm{~m}^{3} / \mathrm{d}$ of the total sewage volume of the city $\left(60,000 \mathrm{~m}^{3} / \mathrm{d}\right)$ drains to the groundwater via the poorly developed septic tanks and house gardens. This amount $\left(50,000 \mathrm{~m}^{3} / \mathrm{d}\right)$ is estimated by (Ghodeif and Geriesh, 2006).

Figure (11) shows The performance of injection wells in repelling the interface toe, using different values of annual injection rates $\left(Q_{j}\right)$ equal $1,2,3,4,5$ and $6 \mathrm{MCM}$ after times equal 5, 10, 20, 30, 50, and 100 years. As evident from this figure, the performance of the injection wells depends on both the rate of injection and the duration. When the annual injection rate of treatment water in QADWA is equals to $1 \mathrm{MCM}$ (Figure 11-a), the reduction distance of saltwater-freshwater interface, calculated from its initial position, at the end of 10 years $\left(=t_{1}\right), 30$ years $\left(=t_{2}\right)$, and 50 years $(=$ $\left.\mathrm{t}_{3}\right)$ are equal $1.75,2.5$, and $3 \mathrm{Km}$, respectively. The average rates of saltwater repulsion per 10 years during $\mathrm{t}_{1}, \mathrm{t}_{2}-\mathrm{t}_{1}$, and $\mathrm{t}_{3}$ $\mathrm{t}_{2}$ are found to be $1.75,0.40$, and $0.25 \mathrm{Km}$ respectively. This means that at the initial stages, the movement of the interface toe due to the injection of water is strong, and when the time advanced the movement of the interface starting to slow down until reaching to the steady state. On the other side, the performance of the injection wells is improved with the increasing rate of injection. For example, when the annual injection rate $Q_{j}=3 \mathrm{MCM}$, the wells are able to achieve $23 \%, 45 \%$, and $59 \%$ of saltwater repulsion within the period $t_{1}, t_{2}$, and $t_{3}$, Figure (11-c). Also, when the annual injection rate $Q_{j}=6 \mathrm{MCM}$, the percentage of reduction increased to $43 \%, 75 \%$, and $90 \%$ of saltwater repulsion within the period $t_{1}, t_{2}$, and $t_{3}$, Figure (11-f). From all drawings in this figure it can be shown that, increasing the total amount of injected water decreases the intruded zone until it reaches a certain value, and any increase in the injection rate has low effect on the reduction of the interface toe.

To obtain the maximum expected injection rate in the QADWA, the average distance of intruded zone has to be calculated for consecutive increasing rates of injection, equal to $100 \mathrm{~m}^{3} / \mathrm{day}$, corresponding to the previous mentioned times (i.e. 5, 10, 20, 30, 50 , and 100 years) until the reduction in intruded zone became constant or nearly constant, Figure (12). This figure represents the relationship between the location of interface toe $(D)$ (where, $D$ represents the average distance between the location of interface toe and the sea shore line) (or in other words, average intruded zone) and the quantity of injected water $\left(Q_{j}\right)$. From this figure, it can be seen that, for increasing the value of the injected water, the intruded zone decreases. Also, with increasing the period of injected water, the intruded zone decreases. The relationship between the location of interface toe $(D)$ and the quantity of injected water $\left(Q_{j}\right)$ is modeled corresponding to each pre-specified time and it is found that the best fitting curve for each one is a polynomial of degree five. Figure (13) shows the approximation for the derivative of each polynomial obtained. It illustrates the fact that for higher values of injection water, the magnitude of the rate of change in distance is decreasing. This is shown as the tangent to the data curve is almost horizontal near the end, Figure (12). Thus, the injection stop is may be chosen when the value of the magnitude of approximated derivative equals a small value $(\alpha)$. For example, if $(\alpha)$ is taken equal to ($0.0001)$, the corresponding value of injected 
treatment water is equal to $14,12.8,9.7$, and 7.5 MCM after 20, 30, 50, and 100 years.

The corresponding total costs for injected water can be estimated by the following equation (Qahman and Larabi, 2006):

$F=Q_{j} *\left(C_{P W}+C_{R}\right)+D_{R} * C_{D W}$

in which; $F$ is the total cost of injection (\$); $Q_{j}$ is the injection rate $\left(\mathrm{m}^{3} / \mathrm{s}\right) ; C_{P W}$ is the price of water $\left(\$ / \mathrm{m}^{3}\right) ; C_{R}$ is the cost of

\section{Conclusion}

In this research, a two-dimensional numerical model is developed for simulating both the groundwater flow and saltwater intrusion of a case study of Quaternary Aquifer in Delta Wadi El-Arish (QADWA), Sinai. The standard numerical procedure (FEM) is adopted to solve the governing equations for the case study. The assumption of sharp interface between saltwater and freshwater is adopted. The model is initially calibrated to simulate the QADWA under different operational scenarios. The proposed study shows the aquifer response to changes in recharge and total rate of pumped water, and their effects on saltwater intrusion. Different scenarios are investigated for the period between 1962 and 2006, to predict future situations and the salinization risk from saltwater intrusion. In this study, for the first time, saltwater intrusion in QADWA is mitigated by injected treatment wastewater through injection wells located at the initial position of interface toe (at distance about 12 $\mathrm{Km}$ from the sea side). The performance of injection wells is found depends on both the injection rate and the duration. During the initial stage of injection, the movement of interface toe is vigorous, and slows down with times as it approaches the steady state. Also, increasing the total amount of injected water decreases the intruded zone until reaches at a certain value; and any increase in the injection rate has insignificant effect on the reduction of the interface toe. In QADWA the maximum expected value of the injected water is mathematically determined which are found equal to 14 , 12.8, 9.7, and 7.5 MCM after 20, 30, 50, 100 years. Also, the corresponding total costs of injected water were estimated 27.76, 25.4, 19.25, and 14.9 Million \$/year respectively.

\section{Acknowledgements}

This paper is a part of the M.Sc. thesis of the third author under supervision of other authors. 

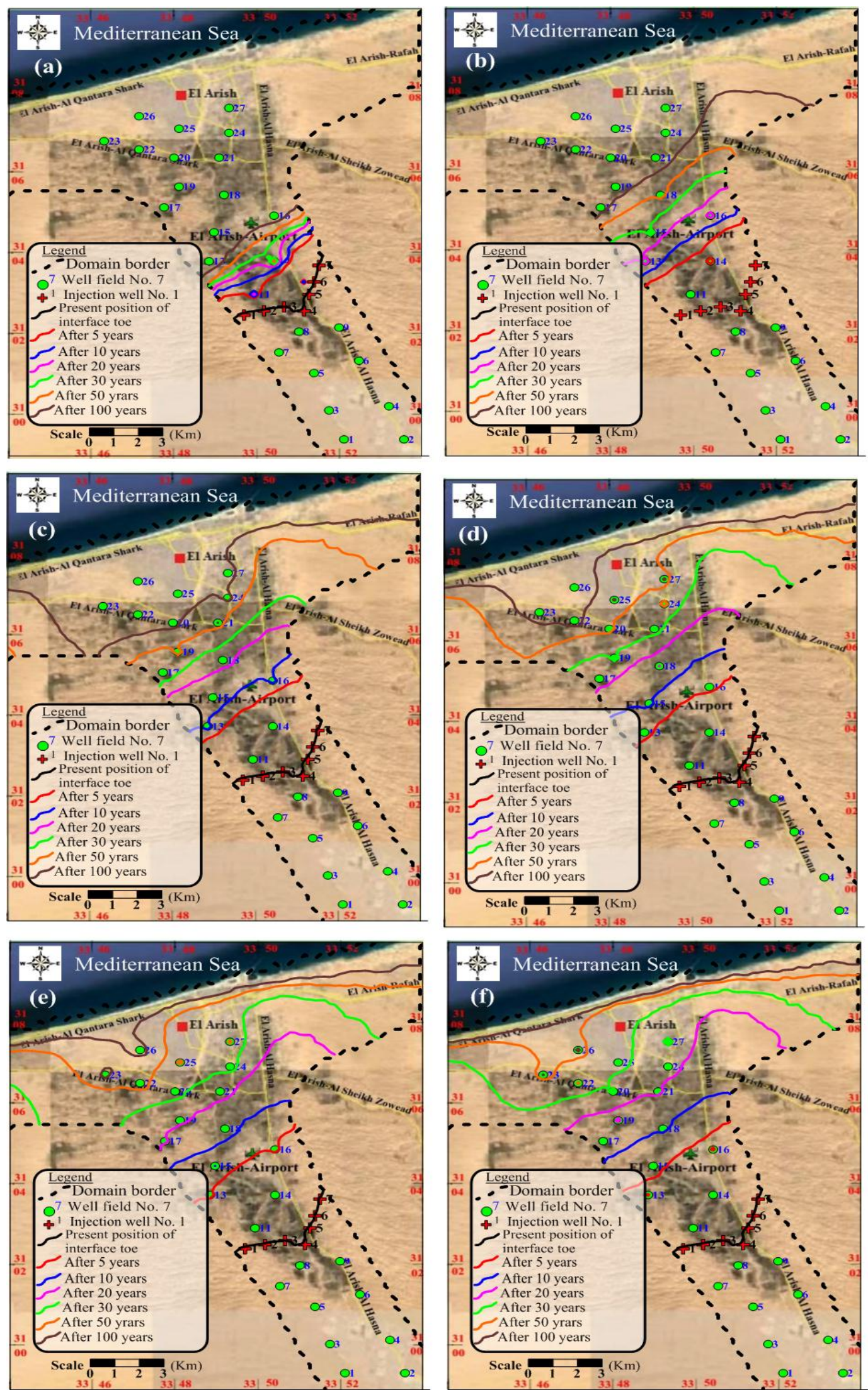

Figure 11: The protected inland interface toe positions from its initial position in the QADWA after different period fordifferent value of annual injection rate where (a) $1 \mathrm{MCM}$; (b) $2 \mathrm{MCM}$; (c) $3 \mathrm{MCM}$; (d) $4 \mathrm{MCM}$; (e) $5 \mathrm{MCM}$; and (f) $6 \mathrm{MCM}$ 


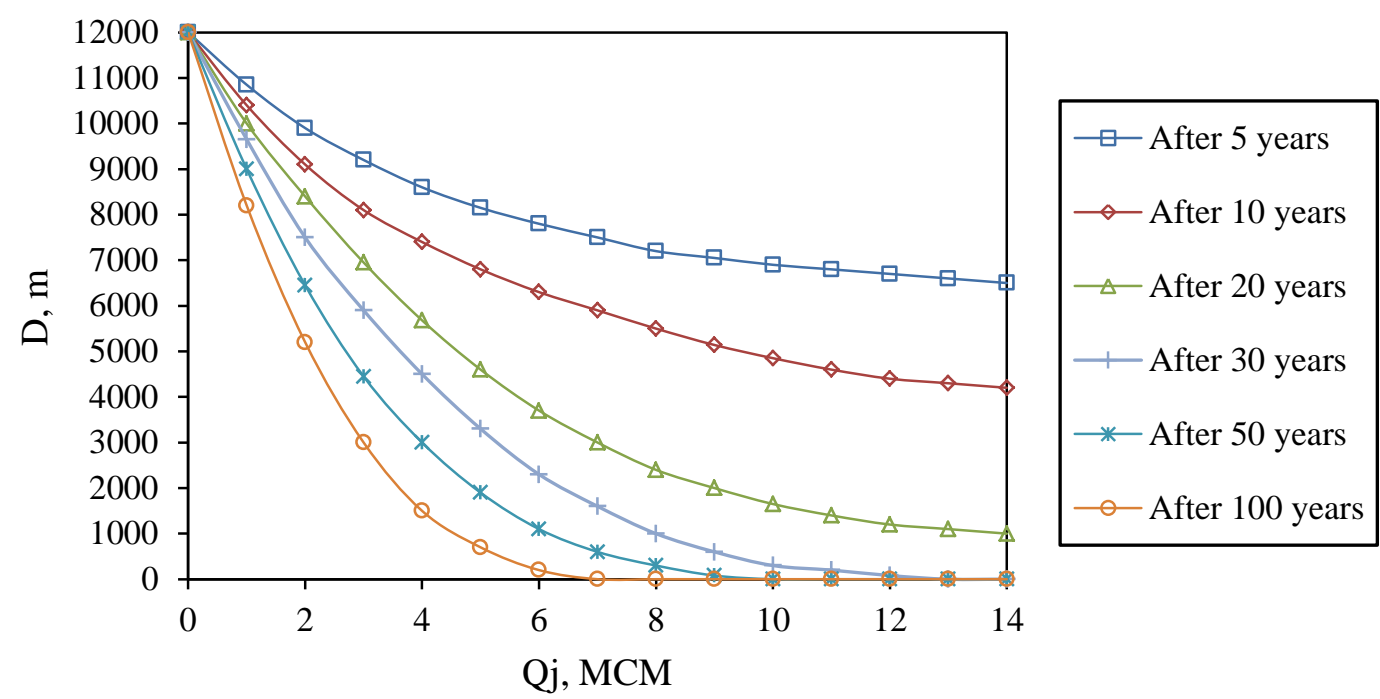

Figure 12: Relationship between the interface toe location and the recharged water quantity in QADWA

$\mathrm{Qj}, \mathrm{MCM}$

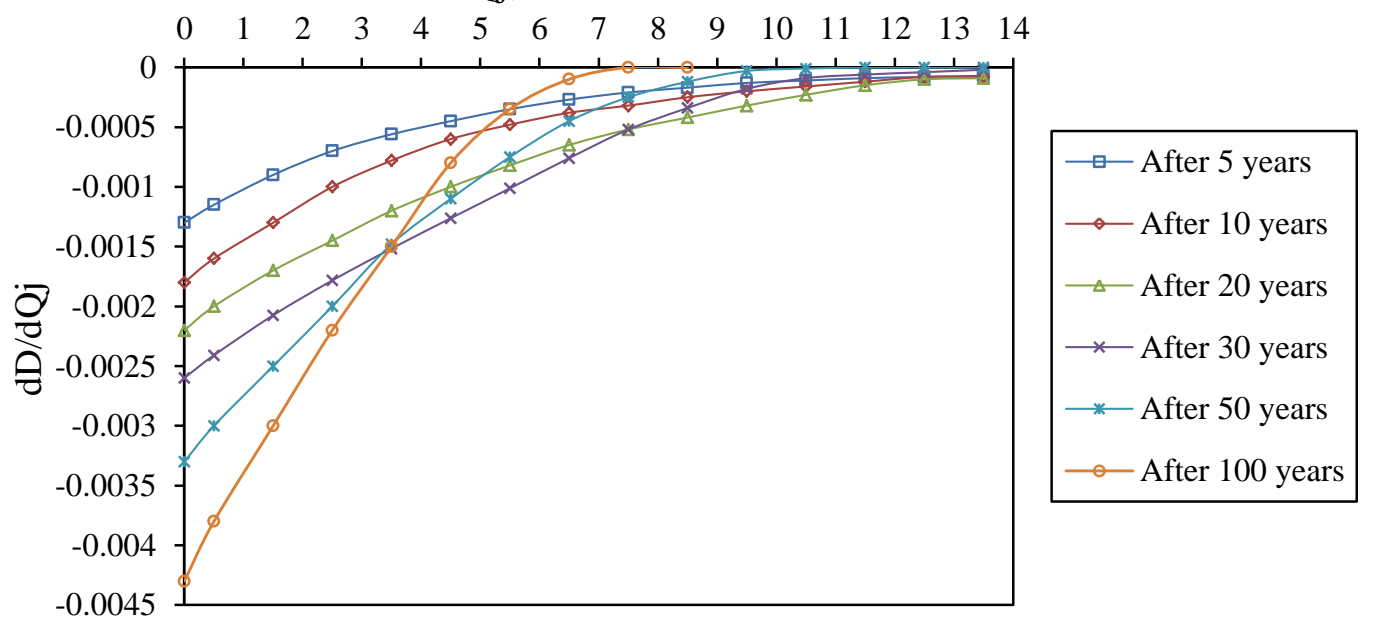

Figure 13: The approximated derivative of the polynomial shown in Figure (12) at different duration

\section{References}

[1] Abdelaziz, R., and Baker, M., (2012). "Inverse Modeling of Groundwater Flow of Delta Wadi El-Arish", Journal of Water Resource and Protection, (4): 432 438.

[2] Abdel-Gawad, H., (1999). "Deterministic and Stochastic Approaches to Inverse Problem of Groundwater Flow and their Effect on Dispersion of Pollution", Ph.D. Thesis Slovak University of Technology, Bratislava, Slovakia,
P. 135.

[3] Bajjali, W., (2005). "Model the Effect of Four Artificial Recharge Dams on the Quality of Groundwater Using Geostatistical Methods in GIS Environment, Oman", Journal of Spatial Hydrology, 5 (2): 1 - 15.

[4] Bakker, M., (2003), "A Dupuit Formation for Modeling Seawater Intrusion in Regional Aquifer Systems", Water Resources Research, 39 (5): SBH (12-1) - (1210). 
[5] Bear, J., (1979). "Hydraulics of groundwater", McGraw-Hill, New York, USA.

[6] Bear, J., Cheng, A.H., Sorek, S., Quazar, D., and Herrera, I., (1999). "Saltwater Intrusion in Coastal Aquifers, Concepts, Methods and Practices", Kluwer Academic Publisher, Dordrecht, The Netherlands. ISBN 0-7923-5573-3.

[7] Bower, J.W., Motez, L.H., and Durden, D.W., (1999). "Analytical Solution for the Critical Conditions of Saltwater Upconing in a Leaky Artesian Aquifer", Journal of Hydrology, Elsevier, 22: 43 - 54.

[8] Brutsaert, W., and Ibrahim, H.A., (1966). "Research note on the first and second linearization of the Boussinesq equation", Grophys. J. R. Astron. Soc., 11: 549 - 554.

[9] Burnett, D.S., (1987). "Finite Element Analysis from Concepts to Application", AT\&T Bell Laboratories, P. 844.

[10] El-Ganainy, M.A., El-Fitiany, F.A., El-Afify, M.M., and Shuluma, Z.M., (1995). "Effects of Pumped Well on Saltwater Intrusion in Coastal Aquifers", Alexandria Engineering Journal, 34 (1): C65 C74.

[11] El-Ghandour, H.A., (2005). "Analysis and Optimization of Saltwater Intrusion in Coastal Aquifers", M.Sc. Thesis, Mansoura University, Mansoura, Egypt, P. 177.

[12] Gad, M.I., El-Sheikh, A.E., ElMagheaby, M.S., (2009). "Application of Mathematical Modeling in the Study of Saltwater Intrusion in the Coastal Quaternary Aquifer, Delta Wadi El-Arish, Egypt" Egyptian Journal of Aquatic Research, 35 (2): 69 - 85.

[13] Ghodeif, K., and Geriesh M.H., (2006). "Contamination of Domestic Groundwater Supply of El-Arish City, North Sinai, Egypt",
Proc. $7^{\text {th }}$ Conf. Geol. Sinai Develop., Ismailia, 171-188.

[14] Goswami, R.R., Clement, T.P., (2007). "Laboratory-Scale Investigation of Saltwater Intrusion Dynamics", Water Resources Research, 43, W04418.

[15] Hantush, M.S., (1968). "Unsteady Movement of Fresh Water in Thick Unconfined Saline Aquifer", Bull. Int. Assoc. Sci. Hydrol., XIII(2): 40 -60 .

[16] Harne, S., Chaube, U.C., Sharma, S., Sharma, P., and Parkhya, S., (2006). "Mathematical Modeling of Saltwater Transport and its Control in Groundwater", Natural and science, $4: 32-39$.

[17] Hassan, S.S., (2010). "Impact of Flash Floods on the Hydrogeological Aquifers System at Delta Wadi El-Arish (North Sinai)", Fifteenth International Water Technology Conference (IWTC), Alexandria, Egypt.

[18] Japan International Cooperation Agency (JICA), (1992). "North Sinai Groundwater Resources Study in Arab Republic of Egypt", Final Report, P. 214.

[19] Javadi, A.A., Abd-Elhamid, H.F., and Farmani, R., (2012). "A Simulation-Optimization Model to Control Saltwater Intrusion in Coastal Aquifers Using Abstraction/Recharge Wells", International Journal for Numerical and Analytical Methods in Geomechanics, 36 (16): 1757 1779.

[20] Liles, M., Thomas, S., and Sovich, T., (2001). "Saltwater Intrusion in Orange County, California: Planning for the Future", Proceeding of the $1^{\text {st }}$ International Conference and Workshop on Saltwater Intrusion and Coastal Aquifers, Monitoring, Modeling, and Management (Morocco).

[21] Mahesha, A., (1996), "Transient 
Effect of Battery of Injection Wells on Saltwater Intrusion", Journal of Hydraulic Engineering, ASCE, 122 (5): $266-271$.

[22] Mukhopadhyay, A., Al-Awadi, E., Oskui, R., Hadi, K., Al-Ruwaih, F., Turner, M., and Akber, A., (2004). "Laboratory Investigations of Compatibility of the Kuwait Group Aquifer, Kuwait, with Possible Injection Waters", Journal of Hydrology, 285: 158 - 176.

[23] Qahman, K., and Larabi, A., (2006). "Evaluation and Numerical Modeling of Seawater Intrusion in the Gaza Aquifer (Palestine)", Hydrology Journal, 14 (5): 713 728.

[24] Rastogi, A.K., Choi, G.W., and Ukarande, S.K., (2004). "Diffused Interface Model to Prevent Ingress of Saltwater in Multi-Layer Coastal Aquifers", Journal of Special Hydrology, 4 (2): 1 - 31.

[25] Saad, K.F., (1981), "Hydrology of Groundwater in Wadi El-Arish, North Sinai", Unpublished Internal Preliminary Report, Desert Research Institute, Submitted to the General Authority for Rehabilitation Project and Agricultural Development at 1962 and Reprinted at 1981, P. 38. (In Arabic).

[26] Sabi, M.A., Smedt, F., and Larabi, A., (2001). "A Generalized Approach for Modeling 3D Transient Free Moving Boundaries in Coastal Aquifers", Proceeding of the $1^{\text {st }}$ International Conference and Workshop on Saltwater Intrusion and Coastal Aquifers, Monitoring, Modeling, and Management (Morocco).

[27] Sabi, M.A., Larabi, A., and De Smedt, F., (1998). "Modeling Saltwater Intrusion by a 3-D Sharp Interface Finite Element Model", Transactions on Ecology and the Environment, 17: 1743 - 3541 .
[28] Sherif, M., and Kacimov, A., (2008). "Pumping of Brackish and Saline Water in Coastal Aquifers: an Effective Tool for Alleviation of Saltwater intrusion", Proceeding of $20^{\text {th }}$ SWIM, Naples, Florida, USA.

[29] Strack, O.D.L., (1989). "Groundwater mechanics", Prentice-Hall, Inc. P. 732.

[30] Taha, A.A., (1968). "Geology of Water Supplies of El-Arish - Rafah Area, Northern Sinai, Egypt", M.Sc. Thesis, Faculty of Science, Cairo University, Egypt.

[31] Taigbenu, A.E., Liggett, J.A., and Cheng, A.H-D., (1984). "Boundary Integral Solution to Saltwater Intrusion into Coastal Aquifers", Water Resource Res., 20: 1150 1158.

[32] Todd, D.K., (1974). "Salt-Water Intrusion and its Control", Water Technology/Resources. Journal of American Water Works Association, 66 (3): $180-187$.

[33] Van Meir, N., Jaeggi, D., Herfort, M., Low, S., Lods, G., Pezard, Ph., and Gouze, Ph., (2004). "Development of a Test Site for the Investigation of Saltwater Intrusion Process in a Karstified Limestone Aquifer (Campos Mallorca, Spain)", Proceeding of the $18^{\text {th }}$ Salt Water Intrusion Meeting, Cartagena (Spain)

[34] Wang, J., and Tsay, T., (2001). "Tidal Effect on Groundwater Motion", Transport in Porous Media, 43: 159-178. 